\title{
Performance and Behaviour of Ground Granulated Blast Furnace Slag Imparted to Geopolymer Concrete Structural Elements and Analyzed with ANSYS
}

\author{
Maria Rajesh Antonyamaladhas, ${ }^{1}$ Selvamony Chachithanantham, ${ }^{2}$ \\ and Anandakumar Ramaswamy ${ }^{3}$ \\ ${ }^{1}$ Anna University, Chennai, Tamil Nadu, India \\ ${ }^{2}$ Department of Civil Engineering, PSN College of Engineering and Technology, Tamil Nadu, India \\ ${ }^{3}$ Department of Civil Engineering, MBCET, Athuvali, Tamil Nadu, India
}

Correspondence should be addressed to Anandakumar Ramaswamy; anandakumar.mtech@gmail.com

Received 5 June 2016; Revised 21 July 2016; Accepted 4 August 2016

Academic Editor: Ying Li

Copyright (C) 2016 Maria Rajesh Antonyamaladhas et al. This is an open access article distributed under the Creative Commons Attribution License, which permits unrestricted use, distribution, and reproduction in any medium, provided the original work is properly cited.

\begin{abstract}
This paper deals with the behaviour of geopolymer concrete using ground granulated blast furnace slag and steel fibre to compare with M40 grade cement concrete. The cast GPC specimens were placed in a hot curing chamber at $60^{\circ} \mathrm{C}$ temperature for 24 hours and tested after 1, 7, 14, and 28 days of ambient curing to find the strength and durability of hardened concrete. The optimum value of compressive strength was attained at 12 Molarities. Fly ash was replaced by GGBS in GPC with different proportions such as $0 \%$ to $60 \%$ at $5 \%$ interval; the optimum strength value was obtained on $40 \%$ replacement. From the test results, the compressive, splittensile, and flexural strength of GPC specimens were 20\%, 43\%, and 53\% higher than those of the control specimens. Based on the optimum strength mix proportion, the structural elements were cast to investigate the stress-strain relations. The GPC beam and L-section showed 33\% and 16\% higher value. From the results of acid and sulphate resistance tests, it was found that the strength and weight ratio of GPC were higher than the control specimens. From the simulations, it was found that the experimental test results were approximately equal to the ANSYS.
\end{abstract}

\section{Introduction}

Concrete is the world's most versatile, durable, and reliable construction material. Ordinary Portland cement (OPC) generates carbon dioxide which pollutes the atmosphere and hence, to reduce greenhouse gas emissions and also to develop an ecofriendly environment, geopolymer concrete (GPC) is chosen as an alternative material. Geopolymer binder is formed when the alkali activator solution reacts with fly ash. The mineral admixtures of GPC such as low calcium fly ash and ground GGBS are rich in silicon and aluminum which are made to react with an alkaline solution to form a paste that binds the loose coarse and fine aggregates. Corrugated steel fibre is used along with admixtures to resist impact and fatigue.
Usage of water is restricted but a superplasticizer is used in GPC. From the experiments, GPC products possess better durability and strength properties than conventional concrete (CC).

Skazlić et al. [1] examined the fibre reinforced-concrete performance which contains $30 \mathrm{~kg} / \mathrm{m}^{3}$ of steel fibres. An optimum fibre reinforced-concrete composition, with the mentioned quantity of steel fibres, was selected and, after hardening, the FRC resistance to bending load was tested. In addition to testing influence of hybrid steel fibres on fibre reinforced-concrete properties, the influence of fibre orientation was also analyzed. Arioz et al. [2] proved that the geopolymer has excellent mechanical properties and durability, good chemical resistance, and low shrinkage and is environmentally friendly. In this experimental research, 
class $\mathrm{F}$ fly ash was activated by $4 \mathrm{M}, 8 \mathrm{M}$, and $12 \mathrm{M}$ of sodium hydroxide. All the samples were cured at $80^{\circ} \mathrm{C}$ for 15 hours; the geopolymer samples were investigated by a scanning electron microscope (SEM). The result showed the compressive strength of samples increased as the molarity of sodium hydroxide increased. Nath et al. [3] performed experiments for their extensive study on the heat curing process required in GPC which is energy consuming and they may not be feasible to apply in cast in situ concreting. Therefore, development of geopolymer mixtures suitable for curing at normal temperature will widen cast in situ application. So, without using heat curing, all tests were conducted by ambient curing $\left(23^{\circ} \mathrm{C}\right)$. The combinations are OPC, fly ash, and GGBS. Compressive strength increased with the increase of the binder content for fly ash blended with 10\% OPC. The 28-day strength increased from $26 \mathrm{MPa}$ to $58 \mathrm{MPa}$ by increasing the binder content from $450 \mathrm{~kg} / \mathrm{m}^{3}$ to $730 \mathrm{~kg} / \mathrm{m}^{3}$. Sayyad and Patankar [4] analyzed the impact of steel fibres and low calcium fly ash on the compressive, flexural, splittensile, and bond strengths of hardened GPCC. Geopolymer concrete mixes were prepared by alkaline solution to fly ash ratio of 0.35 . Optimum fibre content for the maximum value of various strengths of geopolymer concrete composites is $0.2 \%$. The maximum percentage increase in compressive strength, flexural strength, split-tensile strength, and bond strength is $29.98 \%, 30 \%, 30.05 \%$, and $16.11 \%$, respectively. The proposed equation for the modulus of elasticity yielded excellent result and Poisson's ratio varies between the specified limits. Naghibdehi et al. [5] presented a new method for the manufacturing of reinforced-concrete elements. The objective of this investigation is to evaluate the performance of the functionally graded reinforced-concrete beams exposed to cyclic loading. The steel and polypropylene fibres are used for the preparation of samples. Concrete beams with full composite action are strengthened with 0.5 to $2 \%$ of steel fibres, and functionally graded RC beams contain $1.3 \%$ of steel fibres. The use of the functionally graded method to reinforce concrete increases the dissipated energy due to the applied cyclic loading. Okoye et al. [6] evaluated the performance of five mixes casted and tested using fly ash, kaolin, sodium hydroxide, potassium hydroxide, sodium silicate, and aggregates at different temperatures $\left[40^{\circ} \mathrm{C}, 60^{\circ} \mathrm{C}, 80^{\circ} \mathrm{C}, 100^{\circ} \mathrm{C}\right.$, and $120^{\circ} \mathrm{C}$ ]. The results have shown that the compressive strength increased with increasing temperature, curing time, and type of alkali activators. The replacement of fly ash with $50 \%$ kaolin showed a positive effect on the geopolymerization process and the compressive strength was found to be much higher as compared to CC $\left(\mathrm{M}_{30}\right)$. The compressive strength in the presence of $1 \%$ naphthalene sulphonate superplasticizer was found to be $23.30 \%$ and $30.9 \%$ higher than in the presence of melamine-formaldehyde and polycarboxylate ester, respectively. Maranan et al. [7] presented an assessment report of the strength and serviceability of geopolymer concrete beams reinforced with GFRP bars subjected to four-point static bending test. The result showed that the bending moment capacity at concrete crushing failure of GFRP-reinforced geopolymer concrete beams was 1.2 to 1.5 times greater than that of steel reinforced GPC beam. Ramkumar et al. [8] conducted an experimental study on three GPC mixes of fly ash (50\%) and GGBS (50\%) in the binder stage, which were considered with control GPC mix. GPC mix was added with stainless steel fibre and mild steel fibre. The results showed that the compressive strength is increased by $20 \%$ when steel fibres are utilized. GPC mix with added stainless steel fibres is $57 \%$ more than the control mix and GPC mix with added mild steel fibres is $75 \%$ more than the control mix in terms of splittensile strength. Flexural strength of GPC with added fibres is $24 \%$ more than control mix. Venkatesan and Pazhani [9] presented an experimental study on the strength and durability properties of geopolymer concrete prepared using ground granulated blast furnace slag (GGBS) and Black Rice Husk Ash (BRHA). The geopolymer concrete was prepared with GGBS as the primary binder instead of cement and BRHA was replaced with GGBS at various proportions. Addition of BRHA significantly improves the durability with reduced sorptivity and chloride permeability when compared to the control concrete. Higher corrosion initiation and delayed cracking time were observed up to 20\% BRHA replacement in geopolymer concrete. Yoo et al. [10] evaluated a number of SFRC beams with three different compressive strengths, that is, approximately 49,90 , and $180 \mathrm{MPa}$, and four different fibre volume contents $\left(v_{f}\right.$ of $0,0.5,1.0$, and $\left.2.0 \%\right)$ were fabricated and tested. For the static loads and impact loads, the flexural strength and deflection capacity were obtained by increasing the fibre content and strength, and higher toughness was observed with an increase in the fibre content. The increases in fibre content and strength also led to enhancements in residual flexural performance after impact damage. Finally, the flexural strength became less sensitive to the strain rate (or stress rate) as the strength of concrete increased. Albitar et al. [11] presented the notion that geopolymer binders have been shown to be a potential green replacement for ordinary Portland cement (OPC) in concrete manufacture. This paper presents an experimental study on the behaviour of geopolymer concrete in its both wet and hardened states using class $\mathrm{F}$ fly ash. The experimentally determined results are subsequently compared with prediction models developed for OPC-based concrete. The comparison suggests that existing OPC models provide reasonably accurate predictions of the elastic moduli and stress-strain relationships, whereas they slightly underestimate flexural and splitting tensile strengths.

From the above literature review, it was found out that there was no research carried out using fly ash, GGBS, and corrugated steel fibre for geopolymer concrete (GPC). In this experimental study, the various molarities such as $8 \mathrm{M}, 10 \mathrm{M}$, $12 \mathrm{M}, 14 \mathrm{M}$, and $16 \mathrm{M}$ were taken to investigate the optimum molarity value in GPC. Besides, the cast specimens were cured at $60^{\circ} \mathrm{C}$ constant temperature for increasing the rate of hydration and setting of GPC.

\section{Objectives}

The objective of this paper is to study the strength and durability properties of GPC in order to use it as alternative for conventional concrete (CC). The performance of ground granulated blast furnace slag (GGBS) and steel fibre used in 
TABLE 1: Properties of cement.

\begin{tabular}{lc}
\hline Test conducted & Test result \\
\hline Specific gravity & 3.15 \\
Standard consistency in \% & 28 \\
Fineness (specific surface) in $\mathrm{m}^{2} / \mathrm{kg}$ & 227.6 \\
Initial setting time in minutes & 35 \\
\hline
\end{tabular}

TABle 2: Properties of aggregates.

\begin{tabular}{lcc}
\hline \multirow{2}{*}{ Test conducted } & \multicolumn{2}{c}{ Test results } \\
& Fine aggregate & Coarse aggregate \\
\hline Specific gravity & 2.66 & 2.65 \\
Fineness modulus & 3.1 & 7.2 \\
Water absorption in \% & 0.5 & 0.5 \\
Surface texture & Smooth & Smooth \\
Particle shape & Angular & Angular \\
Impact value in \% & & 18.6 \\
Crushing value in \% & - & 19.5 \\
\hline
\end{tabular}

GPC is to be assessed. The strength properties like compressive strength, split-tensile strength, and flexural strength of GPC specimens compared with CC are to be determined. The strength and weight loss of GPC and CC specimens when immersed in acid and sulphate solution are to be found. The stress versus strain and load versus deformation behaviours and cracks patterns of GPC elements compared with CC elements are to be determined. The strength properties of GPC elements like beam and L-section using ANSYS compared with the experimental results are to be assessed.

\section{Materials and Methods}

For this experimental study, ingredients such as 53 grade ordinary Portland cement, fine aggregate, coarse aggregate, water, steel, fly ash, GGBS, and corrugated steel fibre were used for casting specimens like cube, cylinder, prism, and structural elements such as straight beam and L-beam. The ingredients were tested as per Indian standard codes for finding out the properties. Cement was tested as per IS 12269-1987, aggregates were tested as per IS 383-1970, and steel testing was made as per IS 1786-1985. After testing the ingredient properties, the obtained values are tabulated in Tables 1 and 2, and the mix design proportions are tabulated in Tables 3 and 4 .

In this research, the specific gravity values of mineral admixtures such as fly ash and GGBS were 2.76 and 3.20. CONPLAST SP 430 superplasticizer was used to increase the workability of fresh concrete. Corrugated steel fibre was used to increase the tensile strength of concrete. The alkaline solution is obtained when sodium hydroxide reacts with sodium silicate solution. Commercial grade sodium hydroxide is in pellet form and sodium silicate is in solution form, used with aspect ratio 50. Corrugated steel fibres offer cost efficient concrete reinforcement. Mix proportion: based on the ingredient test results, steel fibre was used to increase the tensile strength of the concrete and also to increase

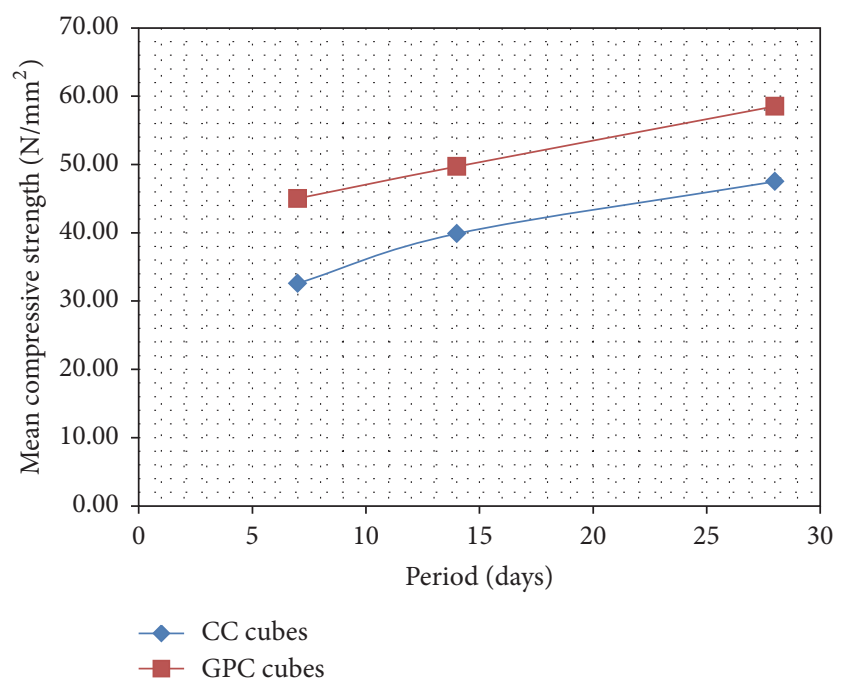

FIGURE 1: Compressive strength developments.

the durability. Corrugated steel fibre was chosen to design the $\mathrm{M}_{40}$ grade concrete mix from IS 10262-2009 for CC specimens and elements casting and testing. For GPC mix proportion trial mix method was adopted.

Conventional Concrete. The mix design was done as per IS10262-2009 and the mix proportion is found in Table 3.

Geopolymer Concrete. The GPC is also called green concrete. The GPC mix design process is developed for low calcium fly ash activated geopolymers using sodium hydroxide and sodium silicate solution, respectively. For GPC, no IS code provisions are available, so trial mix method was adopted. For trial mix method, the mass of combined aggregate was taken as $75 \%$, the ratio of $\mathrm{Na}_{2} \mathrm{SiO}_{3} / \mathrm{NaOH}$ was taken by the mass of 2.5 , and alkaline liquid/fly ash was taken as 0.4 . Based on the experimental results, the GPC mix proportion was obtained in Table 4.

\section{Experimental Study}

Initially, all 15 nos. of cubes, cylinders, and prism specimens were cast using GPC and the characteristic strength on $8 \mathrm{M}$, $10 \mathrm{M}, 12 \mathrm{M}, 14 \mathrm{M}$, and $16 \mathrm{M}$ molarity specimens was tested. The 12 M GPC specimens attained more strength than others. Figures 1, 2, and 3 show the optimum strength of GPC specimens. Table 4 shows $40 \%$ replacement of fly ash with GGBS.

Element Casting and Testing. The main aim of this experimental research is to study the behaviour of GPC structural elements using GGBS and steel fibre. The geopolymer structural elements were cast based on test results of geopolymer specimens which attained optimum strength at $40 \%$ replacement of fly ash by GGBS. The conventional structural elements were cast based on the mix proportion of $\mathrm{M}_{40}$ as per IS 10262-2009. The reinforcement details of structural elements are shown in Figure 4. The structural elements were 
TABLE 3: Mix proportion for conventional concrete.

\begin{tabular}{|c|c|c|c|c|}
\hline Water in litres & Cement in $\mathrm{kg}$ & $\begin{array}{c}\text { Fine aggregate } \\
\text { in } \mathrm{kg}\end{array}$ & $\begin{array}{c}\text { Coarse } \\
\text { aggregate in kg }\end{array}$ & $\begin{array}{l}\text { Superplasticizers in } \\
\mathrm{kg}\end{array}$ \\
\hline 195.16 & 487.89 & 490.575 & 1172.39 & $0.4 \%$ of cement \\
\hline
\end{tabular}

TABLE 4: Mix proportion for GPC.

\begin{tabular}{lccccccr}
\hline $\begin{array}{l}\text { Mineral admixture } \\
\text { Fly ash } \\
\mathrm{kg} / \mathrm{m}^{3}\end{array}$ & $\begin{array}{l}\mathrm{GGBS} \\
\mathrm{kg} / \mathrm{m}^{3}\end{array}$ & $\begin{array}{c}\mathrm{NaOH} \\
\mathrm{kg} / \mathrm{m}^{3}\end{array}$ & $\begin{array}{c}\mathrm{Na}_{2} \mathrm{SiO}_{3} \\
\mathrm{~kg} / \mathrm{m}^{3}\end{array}$ & $\begin{array}{c}\text { Coarse } \\
\text { aggregate } \\
\left(\mathrm{kg} / \mathrm{m}^{3}\right)\end{array}$ & $\begin{array}{c}\text { Fine aggregate } \\
\left(\mathrm{kg} / \mathrm{m}^{3}\right)\end{array}$ & Molarity & Curing temperature \\
\hline 257.16 & 171.44 & 48.97 & 122.43 & 1260 & 540 & $12 \mathrm{M}$ & $60^{\circ}$ \\
\hline
\end{tabular}

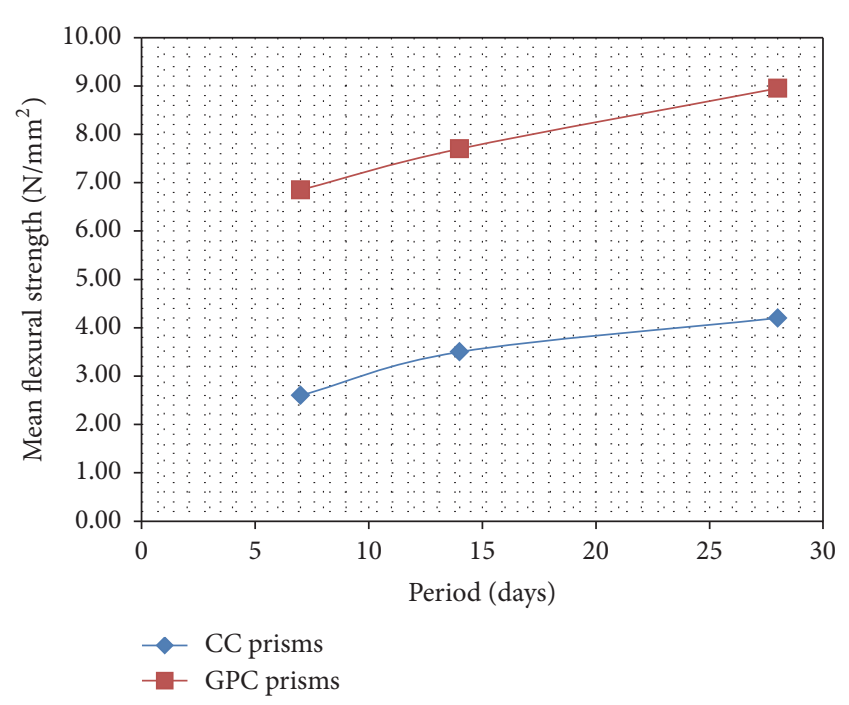

FIgURE 2: Flexural strength developments.

coated with white cement after cleaning the elements and grid line marking was done at a distance of $25 \mathrm{~mm}$ for crack pattern studies. The structural elements were tested by using a loading frame as shown in Figure 5.

The electronic strain gauges are fixed at a particular point for observing the deformation of elements during compressive loading. LVDT is placed under the loading point of the element for measuring the ultimate load, deflection, and strain with respect to time in seconds. From the readings obtained, the crack formation places, patterns, and width were studied. The stress-strain curve was plotted based on experimental results of conventional concrete (CC) and GPC beam and L-beam as shown in Figures 6 and 7. The stresses were determined by the ratio of direct applied load to the cross-sectional area of elements.

The experimental results were compared with analytical results (ANSYS). The procedure of ANSYS is as follows. (i) Modeling of the structural elements such as beam and Lsection based on $x, y$, and $z$ coordinates is to be created; (ii) materials properties are to be fed; (iii) meshing arrangements in grid form are to be made; (iii) load at the centre of each element and support conditions at the base in the case of Lbeam and at both ends in the case of beam are to be applied;

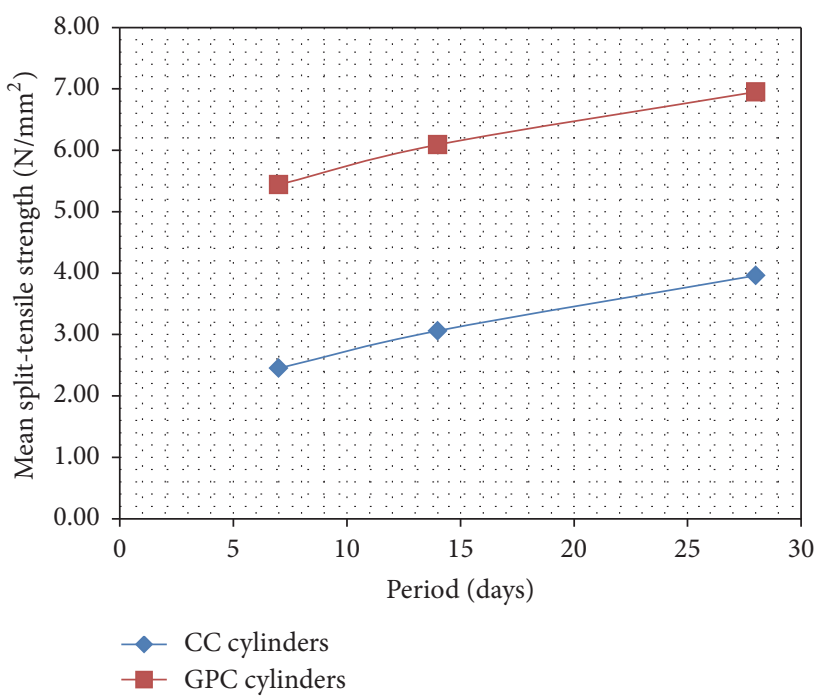

FIGURE 3: Split-tensile strength developments.

(iv) the structural elements are to be analyzed for getting the results. The ANSYS results are shown in Figures 8 and 9.

Table 5 shows the mechanical and physical properties of GPS elements under ultimate loading condition. Young's modulus was determined from direct stress versus strain; strain is taken from LVT. Moment of inertia was determined by (breadth $\left.\times \operatorname{depth}^{3} / 12\right)$ for beam and $\left(I_{G}+A h^{2}\right)$ for Lsection, where $I_{G}$ is the moment of inertia about the centre of gravity, $A$ is the area of section, and $h$ is the centroid of the section. Deflection was determined by ( (load $\times$ effective length $\left.^{3}\right) /(48 \times$ Young's modulus $\times$ moment of inertia $\left.)\right)$ for beam and $\left(\left(\right.\right.$ load $\times$ effective length $\left.{ }^{3}\right) /(3 \times$ Young's modulus $\times$ moment of inertia)) for L-section.

Acid and Sulphate Resistance Test. In the acid resistance test, cube specimens of 36 nos. were cast using $\mathrm{M}_{40}$ grade concrete. After 28 days of water curing, the specimens were dried in the atmosphere for 36 hours and weighed (initial weight), and in CC and GPC specimens were placed in the hot curing chamber at $60^{\circ} \mathrm{C}$ temperature for 24 hours after casting and tested after 28 days of ambient curing in the laboratory in order to find the strength and then kept immersed in $2 \% \mathrm{HCl}$. Diluted solution and $2 \%$ magnesium sulphate solution were 


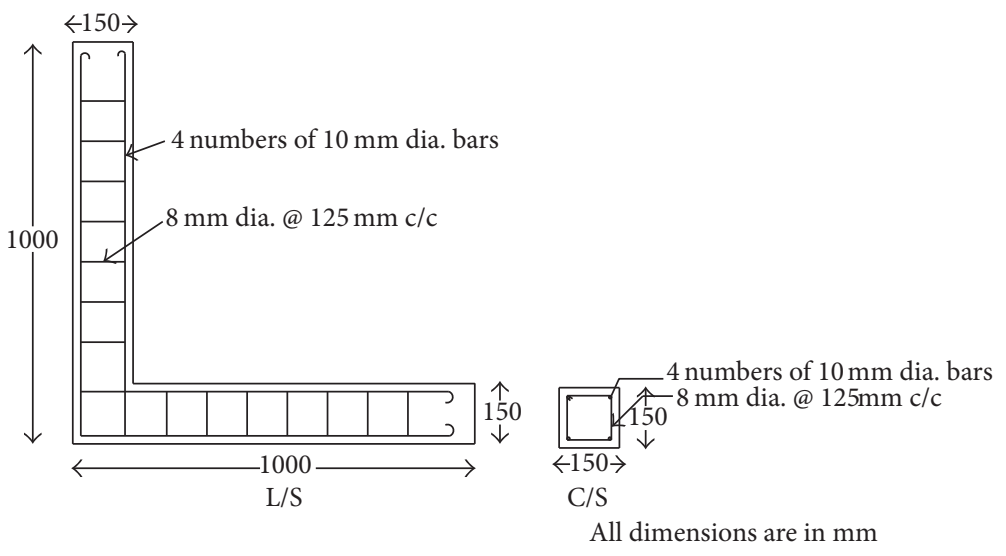

(a)

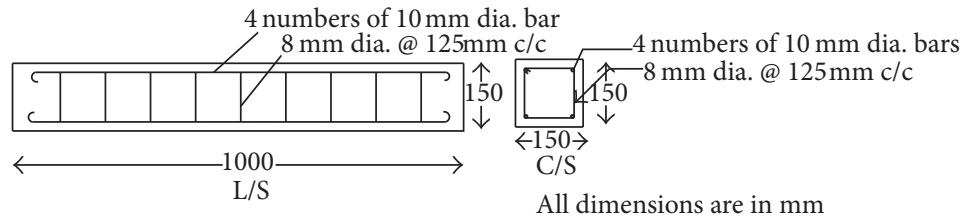

(b)

FIGURE 4: Reinforcement details of elements.
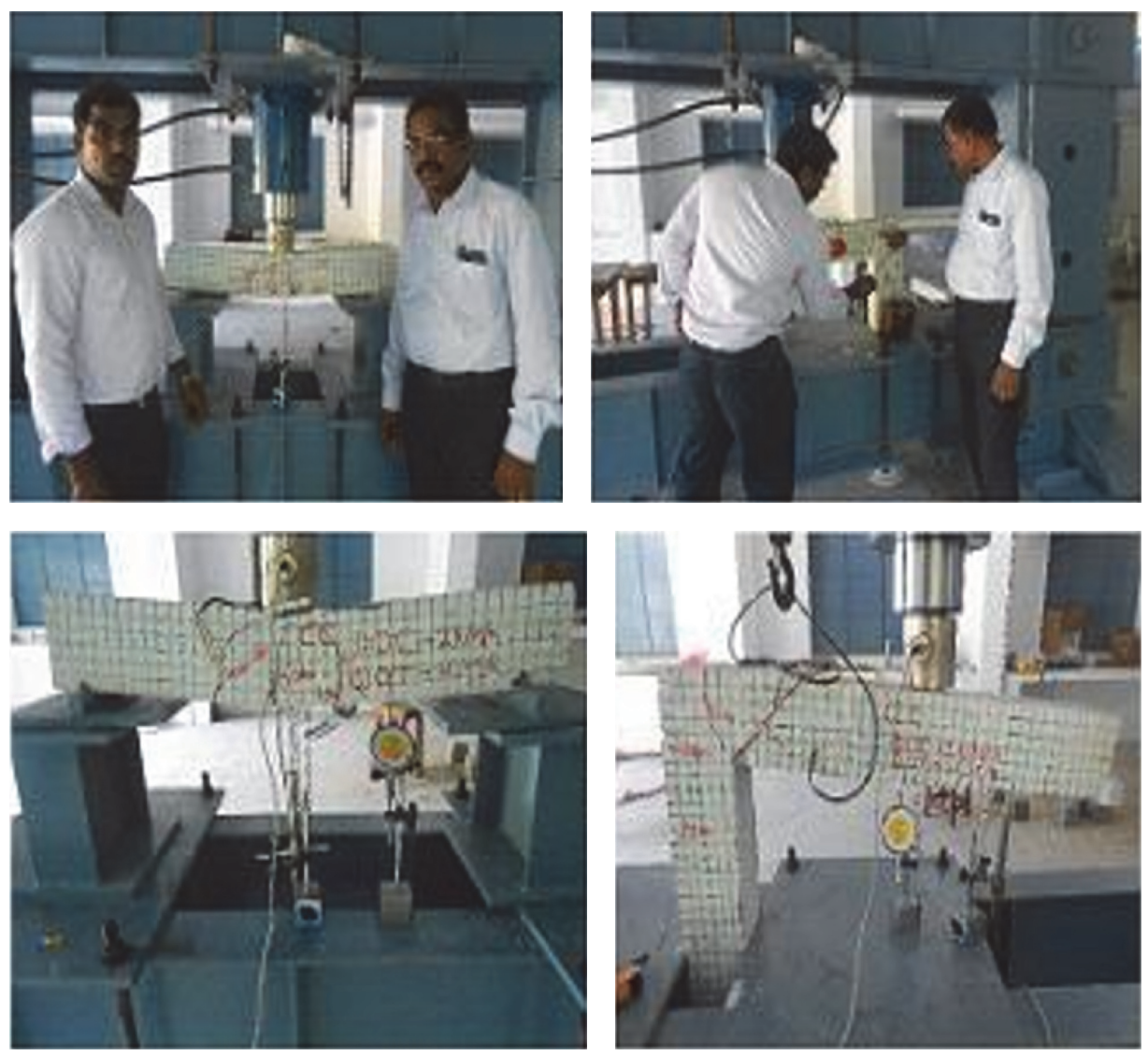

FIgure 5: Testing of GPC and CC elements. 
TABLE 5: Comparison between experimental results, ANSYS results, and mathematical prediction.

\begin{tabular}{|c|c|c|c|c|c|c|}
\hline \multirow{2}{*}{$\begin{array}{l}\text { Structural } \\
\text { elements }\end{array}$} & \multirow{2}{*}{$\begin{array}{l}\text { Failure load } \\
\qquad(\mathrm{N})\end{array}$} & \multirow{2}{*}{$\begin{array}{l}\text { Young's modulus } \\
\qquad\left(\mathrm{N} / \mathrm{mm}^{2}\right)\end{array}$} & \multirow{2}{*}{$\begin{array}{c}\text { Moment of } \\
\text { inertia }\left(\mathrm{mm}^{4}\right)\end{array}$} & \multicolumn{3}{|c|}{ Deflection $(\mathrm{mm})$} \\
\hline & & & & $\begin{array}{l}\text { Experimental } \\
\text { results }\end{array}$ & $\begin{array}{c}\text { Theoretical } \\
\text { results }\end{array}$ & $\begin{array}{c}\text { ANSYS modeling } \\
\text { results }\end{array}$ \\
\hline Beam (CC) & 52500 & 32752.07 & \multirow{2}{*}{$42.19 \times 10^{6}$} & 0.8 & 0.49 & 0.49 \\
\hline Beam (GPC) & 78800 & 35144.31 & & 0.95 & 0.69 & 0.69 \\
\hline L-beam (CC) & 54300 & 32752.07 & \multirow{2}{*}{$2.52 \times 10^{10}$} & 38 & 39.5 & 39.4 \\
\hline L-beam (GPC) & 67500 & 35144.31 & & 42 & 46.0 & 45.7 \\
\hline
\end{tabular}

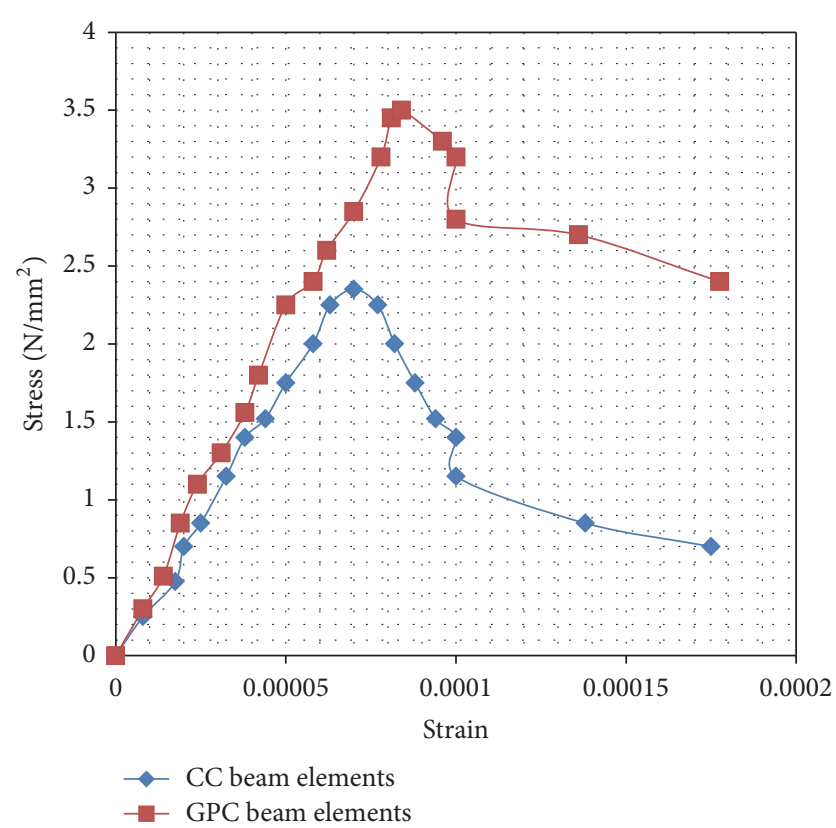

Figure 6: Stress-strain curve for RCC beam.

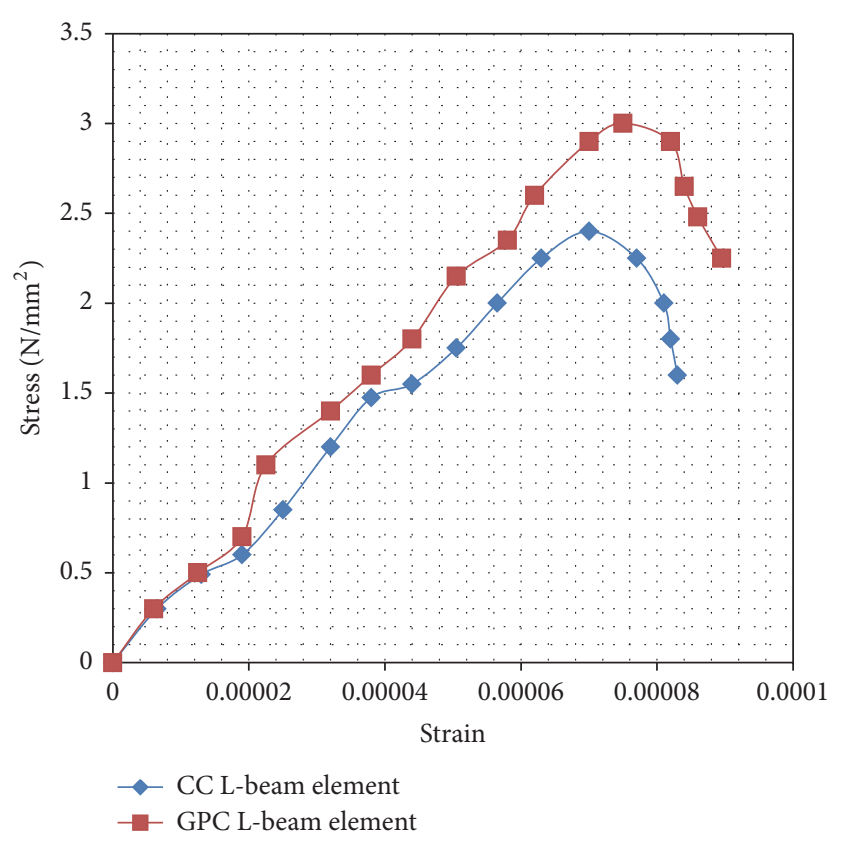

Figure 7: Stress-strain curve for L-beam.
TABLE 6: Details of the experimental program.

\begin{tabular}{lcccc}
\hline $\begin{array}{l}\text { Description of } \\
\text { specimens }\end{array}$ & \multicolumn{4}{c}{$\begin{array}{c}\text { Duration of specimens immersed in } \mathrm{HCl} \\
\text { and Mg sulphate solution }\end{array}$} \\
& 0 days & 28 days & 56 days & 84 days \\
\hline CC specimens & 3 & 3 & 3 & 3 \\
GPC specimens & 3 & 3 & 3 & 3 \\
\hline
\end{tabular}

used as per Table 6 . Figure 10 shows the compressive strength of CC and GPC specimen and performance in the acid and sulphate resistance test for the periods of 28 days, 56 days, and 84 days.

\section{Results and Discussion}

In this study, the strength and durability of GPC structural elements such as beam and L-section were evaluated for finding the deflection, stress versus strain relations, Young's modulus, and flexural strength of GPC and CC. The durability properties such as acid and sulphate resistance tests were conducted for both GPC and CC and results were compared.

The initial test results of cube, cylinder, and prism were shown in Figures 1, 2, and 3. The compressive strength of GPC cube is $20 \%$ higher than of CC cube, the split-tensile strength of GPC cylinder is $43 \%$ higher than of CC cylinder, and the flexural strength of GPC prism is 53\% higher than of CC prism. Based on the above results, the optimum mix proportion was chosen for casting and testing the structural elements such as beam and L-section.

The reinforcement details of beam and L-section are shown in Figure 4. The size of the beam is $1000 \times 150 \times$ $150 \mathrm{~mm}$. The overall, clear, and effective spans are $1000 \mathrm{~mm}$, $700 \mathrm{~mm}$, and $850 \mathrm{~mm}$. Two numbers of $10 \mathrm{~mm}$ diameter reinforcement were provided at tension and compression zone. $8 \mathrm{~mm}$ diameter stirrups were provided at $125 \mathrm{~mm}$ centre to centre.

The ultimate load versus deflection is found by experimental and mathematical testing and ANSYS, shown in Table 5. The maximum ultimate loads in GPC and CC were $78.50 \mathrm{KN}$ and $52.50 \mathrm{KN}$ and their corresponding deflection values were $0.69 \mathrm{~mm}$ and $0.49 \mathrm{~mm}$. The load resisting capacity of GPC beam was 33\% higher than of CC beam and the central deflection of GPC beam was 16\% lower than of CC beam. The load resisting capacity of GPC L-beam was $20 \%$ higher than of CC L-beam and the central deflection of GPC $\mathrm{L}$-section was $10 \%$ lower than of CC L-section. 

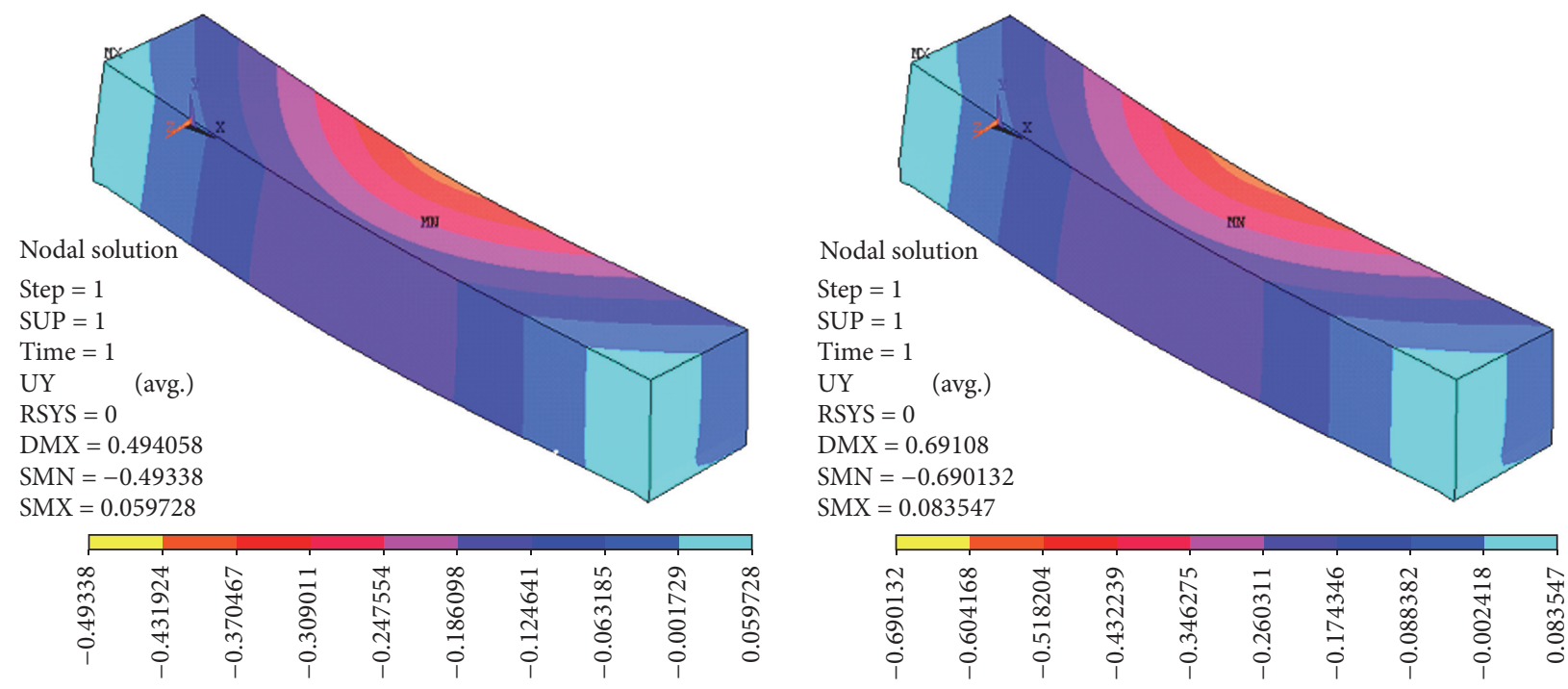

FIgURE 8: Flexural behaviour of RCC beam in CC and GPC.
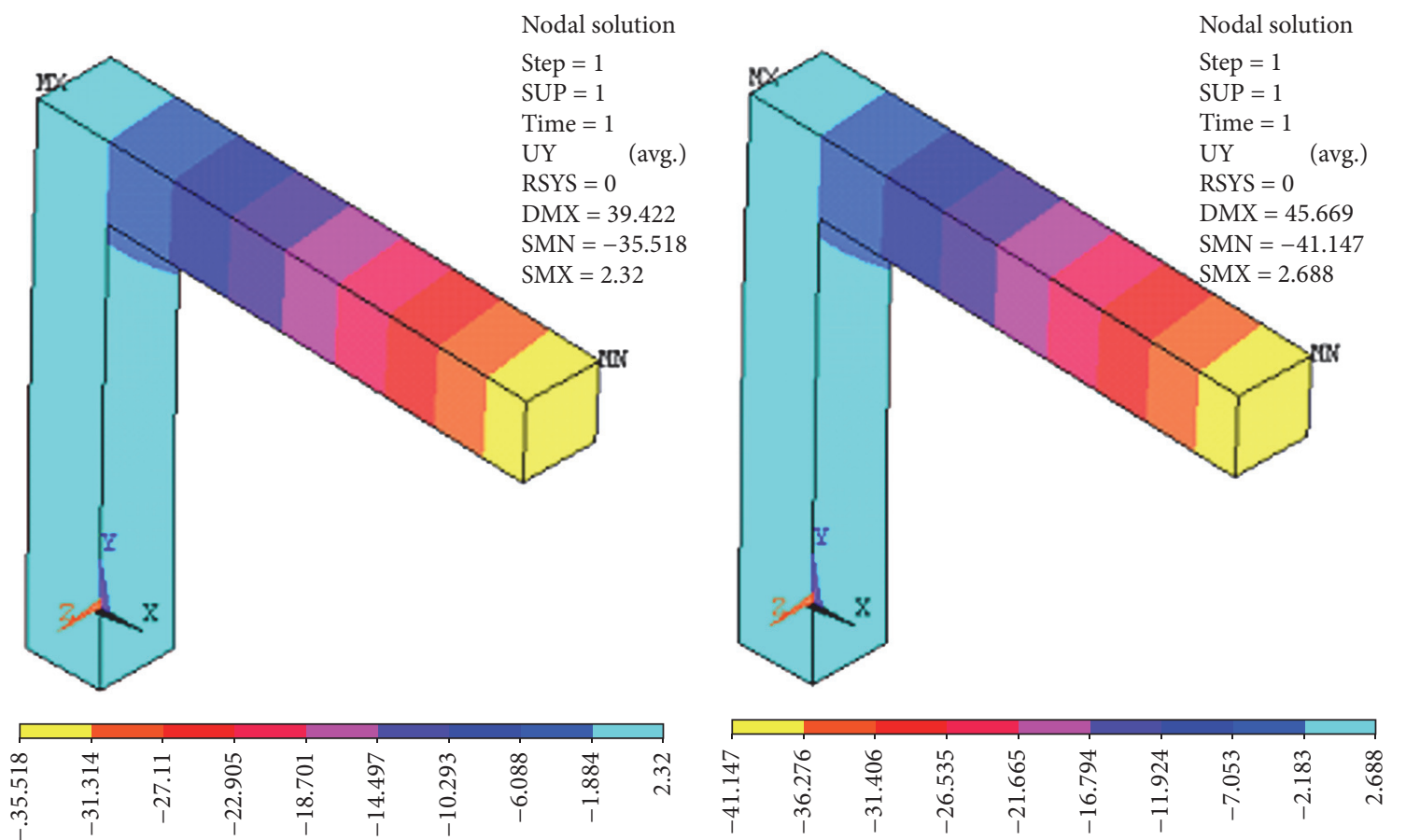

Figure 9: Flexural behaviour of RCC L-beam in CC and GPC.

The comparisons of stress-strain relations in GPC structural elements and CC structural elements are shown in Figures 8 and 9. The experimental results of structural elements such as GPC beam and L-section were 33\% and 20\% higher than CC beam and CC L-section.

The flexural strengths of GPC beam and L-section were compared with CC. The flexural strengths of GPC straight beam and L-beam were 1.50 times and 1.52 times greater than CC.

The initial cracks were formed at mid span and gradually developed adjacent to the mid span towards the edges. The initial crack occurred due to $18 \mathrm{KN}$ load at mid span and the crack developed adjacent to the mid span up to $52.5 \mathrm{KN}$ load in CC beam. The initial crack occurred due to $23 \mathrm{KN}$ load at mid span and the crack developed adjacent to the mid span up to $78.8 \mathrm{KN}$ load in GPC beam. The crack patterns were formed in the shape of zigzag started from mid span for both GPC and CC beam. In L-section, the initial crack occurred at the junction between flange and web at $12 \mathrm{KN}$ and $17 \mathrm{KN}$ load in CC and GPC, respectively. The crack developed adjacent to the junction between web and flange at $54.3 \mathrm{KN}$ and $67.5 \mathrm{KN}$ in CC and GPC elements, respectively. 


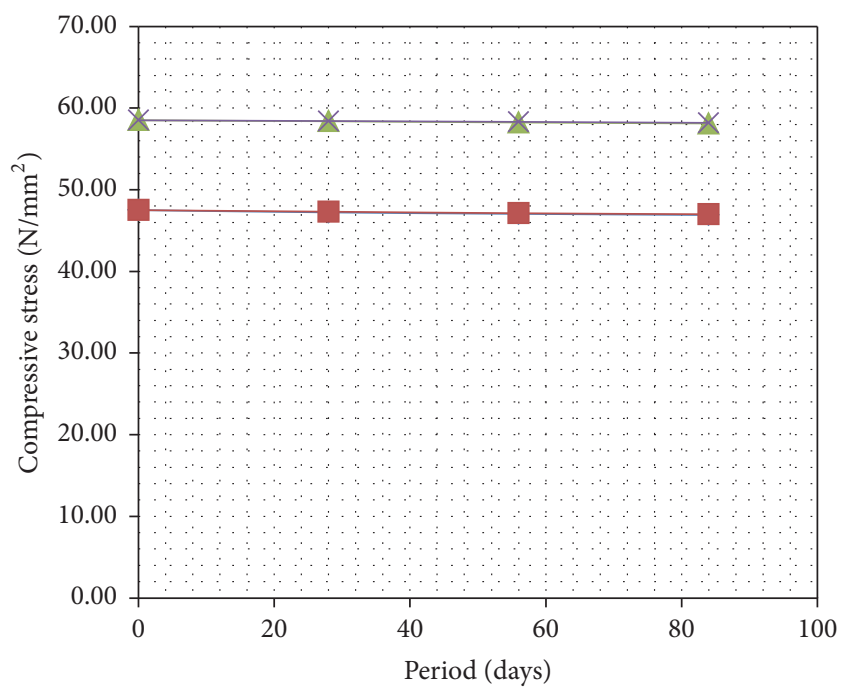

$\neg$ CC avg. compressive strength immersed in acid in $\mathrm{N} / \mathrm{mm}^{2}$

- CC avg. compressive strength immersed in sulphate in $\mathrm{N} / \mathrm{mm}^{2}$

- GPC avg. compressive strength immersed in acid in $\mathrm{N} / \mathrm{mm}^{2}$

$\leftarrow$ GPC avg. compressive strength immersed in sulphate in $\mathrm{N} / \mathrm{mm}^{2}$

Figure 10: Acid and sulphate curing.

The durability tests such as acid and sulphate resistance test results were shown to be good because the weight and strength of GPC were attained at 1.015 and 1.06 times greater than CC specimen. The result of acid resistance test shown in Figure 10 was also good because the weight and strength of GPC specimen were attained at 1.015 times and 1.06 times greater than CC specimen.

From Table 5, the deflection of elements was found out experimentally on every $5 \mathrm{KN}$ loading interval. Experimental deflections were cross-checked theoretically and also with ANSYS modeling. Experimental results were higher than theoretical and modeling results.

The strength and durability tests were carried out in the laboratory as per IS 516-1959. The strength of GPC elements is increased with the effect of molarity, fly ash, and GGBS from initial test results. The fly ash and GGBS are rich in silica and alumina and act as a good reactive powder with alkaline solution. In $12 \mathrm{M}$, the solution gets good concentration compared with other molarities from the initial test results.

\section{Conclusions}

From the experimental research results, it is concluded that GPC structural elements withstand higher load carrying capacity, resistance to deformation, and deflection than the CC elements.

From the initial test results, it is found that compressive strength of GPC cube, split-tensile strength of GPC cylinder, and flexural strength of prism were 20\%, 43\%, and 53\% increased compared with CC specimens.

It is determined that the flexural strengths of GPC structural elements such as straight beam and L-beam were increased by $50 \%$ and $52 \%$ compared with CC. The deflection was reduced to $16 \%$ and $10 \%$ compared with CC. The stress versus strain relation of GPC was compared with CC and it is found that it increases by $34 \%$ and $20 \%$ in GPC compared with CC. The durability properties such as acid and sulphate resistance tests were conducted for both GPC and CC and results were compared and it is found that GPC resists acid and sulphate attack $19 \%$ and $20 \%$ better than CC.

All the experimental results were compared with ANSYS software results and it is found that there is an only negligible variation in both GPC and CC elements.

Geopolymer technology not only contributes to the reduction of greenhouse gas emissions but also reduces disposal costs of industrial waste. Geopolymer technology encourages recycling of waste and finally it will be an important step towards sustainable concrete industry.

\section{Competing Interests}

The authors declare that they have no competing interests.

\section{References}

[1] M. Skazlić, D. Tkalčić, and D. Šomoši, "Optimisation of fibre reinforced concrete for bending load," Gradjevinar, vol. 60, no. 2, pp. 133-140, 2008.

[2] E. Arioz, O. Arioz, and O. Mete Kockar, "An experimental study on the mechanical and microstructural properties of geopolymers," in Proceedings of the 20th International Congress of Chemical and Process Engineering (CHISA '12), pp. 100-105, Prague, Czech Republic, August 2012.

[3] P. Nath, P. K. Sarker, and V. B. Rangan, "Early age properties of low-calcium fly ash geopolymer concrete suitable for ambient curing," in Proceeding of the Chemical, Civil and Mechanical Engineering Tracks of 3rd Nirma University International Conference on Engineering (NUiCONE '12), Elsevier, 2012.

[4] A. S. Sayyad and S. V. Patankar, "Effect of steel fibres and low calcium fly ash on mechanical and elastic properties of geopolymer concrete composites," Indian Journal of Materials Science, vol. 2013, Article ID 357563, 8 pages, 2013.

[5] M. G. Naghibdehi, M. Naghipour, and M. Rabiee, "Behaviour of functionally graded reinforced-concrete beams under cyclic loading," Gradjevinar, vol. 67, no. 5, pp. 427-439, 2015.

[6] F. N. Okoye, J. Durgaprasad, and N. B. Singh, "Mechanical properties of alkali activated flyash/Kaolin based geopolymer concrete," Construction and Building Materials, vol. 98, pp. 685691, 2015.

[7] G. B. Maranan, A. C. Manalo, B. Benmokrane, W. Karunasena, and P. Mendis, "Evaluation of the flexural strength and serviceability of geopolymer concrete beams reinforced with glassfibre-reinforced polymer (GFRP) bars," Engineering Structures, vol. 101, pp. 529-541, 2015.

[8] G. Ramkumar, S. Sundarkumar, and A. Sivakumar, "Development of steel fibre reinforced geopolymer concrete," International Journal of Advance Research in Science and Engineering, vol. 4, no. 1, pp. 1717-1725, 2015.

[9] R. P. Venkatesan and K. C. Pazhani, "Strength and durability properties of geopolymer concrete made with Ground Granulated Blast Furnace Slag and Black Rice Husk Ash," KSCE Journal of Civil Engineering, vol. 20, no. 6, pp. 2384-2391, 2016.

[10] D.-Y. Yoo, Y.-S. Yoon, and N. Banthia, "Flexural response of steel-fiber-reinforced concrete beams: effects of strength, fiber 
content, and strain-rate," Cement and Concrete Composites, vol. 64, pp. 84-92, 2015.

[11] M. Albitar, P. Visintin, M. S. Mohamed Ali, and M. Drechsler, "Assessing behaviour of fresh and hardened geopolymer concrete mixed with class-F fly ash," KSCE Journal of Civil Engineering, vol. 19, no. 5, pp. 1445-1455, 2015. 

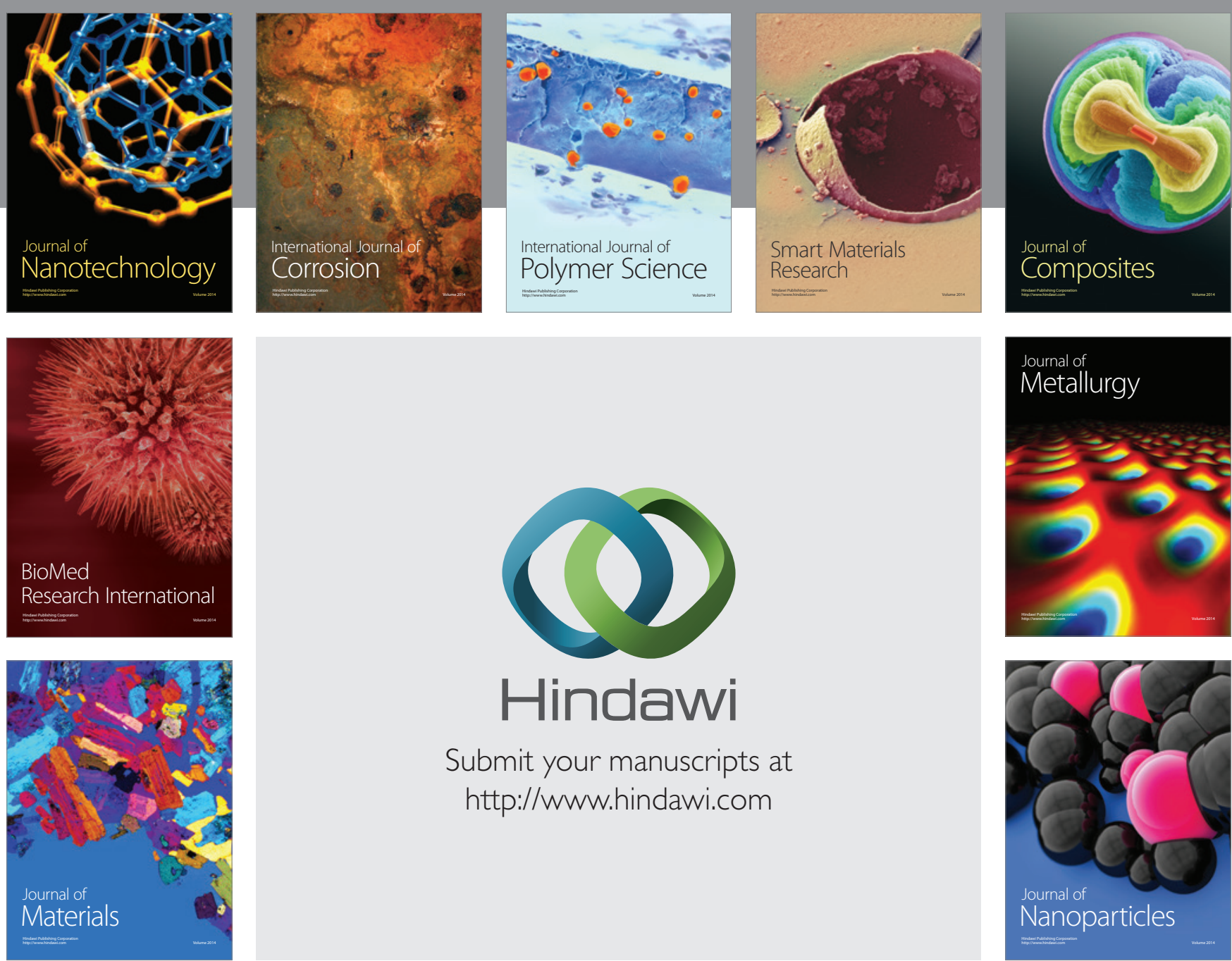

\section{Hindawi}

Submit your manuscripts at

http://www.hindawi.com

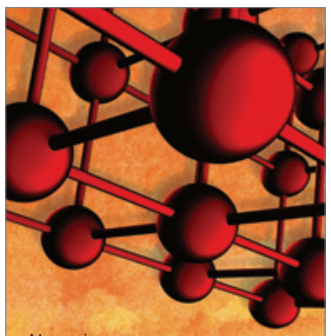

Materials Science and Engineering
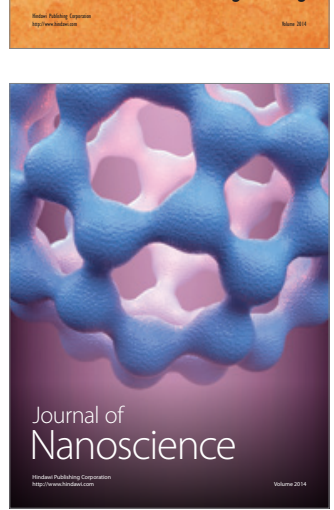
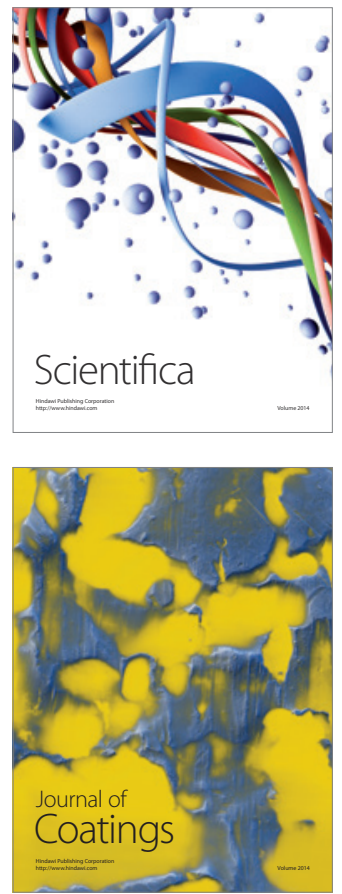
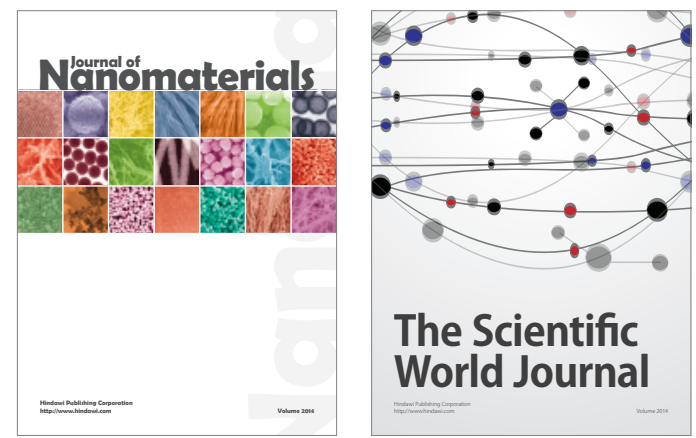

The Scientific World Journal
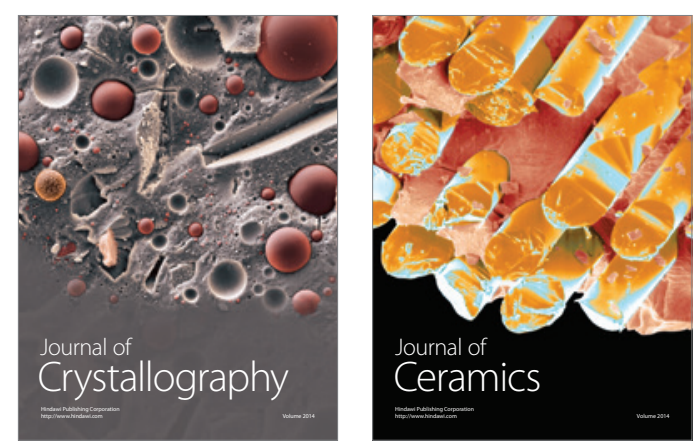
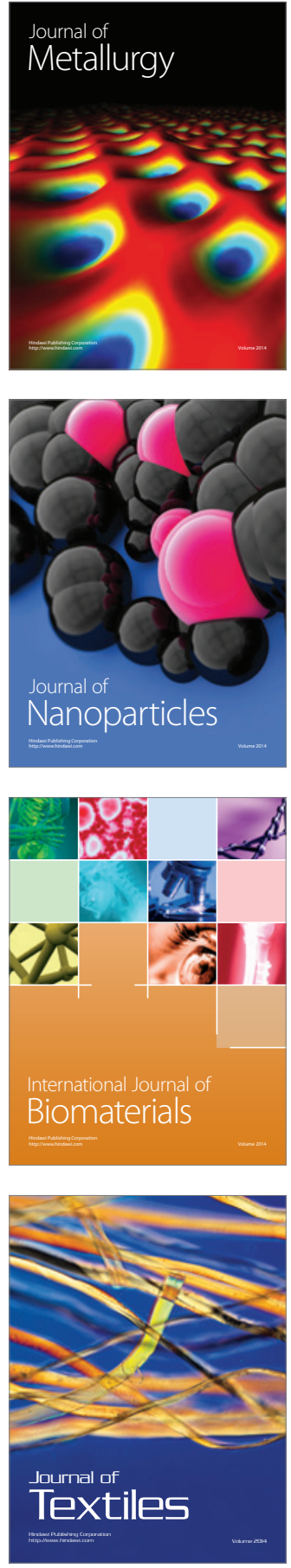